\title{
THE RESONANCE ANALYSIS CAUSED BY.HARMONICS IN POWER SYSTEMS INCLUDING THYRISTOR CONTROLLED REACTOR
}

\author{
Ramazan YÜKSEL ${ }^{*}$ Mehmet UZUNOGLU** Celal KOCATEPE ${ }^{* * *}$ Mehmet ARGIN $^{* * * *}$ \\ *Karayolları 17.Bölge Müdürlüğüu, 80600, Zincirlikuyu, İst., fsmkop@ superonline.com \\ ***1ldız Teknik Ünv., Elk. Müh. Böl., 80750 Beşiktaș, İst., uzunoglu@yildiz.edu.tr, \\ kocatepe@yildiz.edu.tr \\ **** Arizona State Unv., Dept. of Elc. Eng., Power Research Group, Tempe, AZ, USA, \\ argin@asu.edu
}

\begin{abstract}
The static VAR compensators having fixed capacitor thyristor controlled reactor (FC-TCR) used to improve voltage stability in power systems are nonlinear elements. The fixed capacitor group will produce reactive power while the thyristor controlled reactor will consume reactive power in compensators having FC-TCR. Changing the firing angles of TCR provides the reactive power variation of the system since the reactive power production of capacitors is fixed at a determined voltage level. In some cases, the variation of these firing angles will cause the harmonics in the system. In this study, TCR's are discussed to be harmonic sources and the resonance case caused by harmonics has been investigated with Fourier Matrix Model and MATLAB Software.
\end{abstract}

Keywords: Thyristor Controlled Reactor, Harmonics, Resonance

\section{INTRODUCTION}

In recent years, there is a rapid increase of using thyristor-controlled reactors in power systems. Beside many advantages of the thyristor controlled reactors, they cause the flowing of the nonsinusoidal quantities in the system because of their entire power electronics structure [1]. One of the harmonic components of nonsinusoidal quantities may cause resonance.

In a fixed capacitor thyristor controlled reactor (FC-TCR), the reactive power variation of the system is provided by changing the firing angles of thyristors, since the reactive power production of capacitors is fixed at a determined voltage level. The changing of the firing angles will control the fundamental component of the reactor current and thus amplitude of the reactive power [2]. At an operating of the system, there is a need for accurate modeling of the harmonics and in order to understand the resonance problems that harmonics can cause $[3,4]$. Sometimes incorrect selection of the firing angles of the thyristors may cause some disadvantages such as resonance, which will result in inaccurate determination of the active harmonic production of the TCR.

\section{THYRISTOR CONTROLLED REACTOR AS HARMONIC SOURCE}

Thyristor controlled reactors that can provide a continuous, fast reactive power and voltage control may improve performance of power system in many aspects. These aspects are controlling of transient over-voltages at power frequency and preventing of voltage collapse increase in transient stability and decrease in system oscillations. Static 
VAR compensators consist of thyristor controlled reactors that are used for balancing the three phase systems supplying unbalanced loads and for preventing the voltage oscillations caused by short duration.loads in transmission and distribution systems.

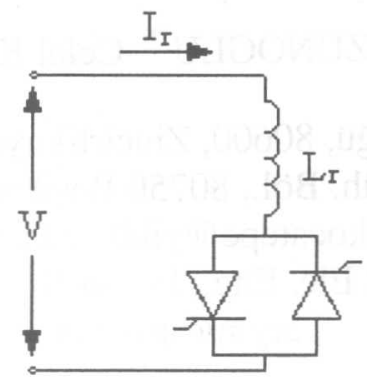

Figure 1. The main elements of thyristor controlled reactor

The thyristor-controlled reactor consists of reactor in series with two parallel inverse thyristors as shown in Figure 1. These thyristors are gated symmetrically and control the fundamental component of current versus time [3].
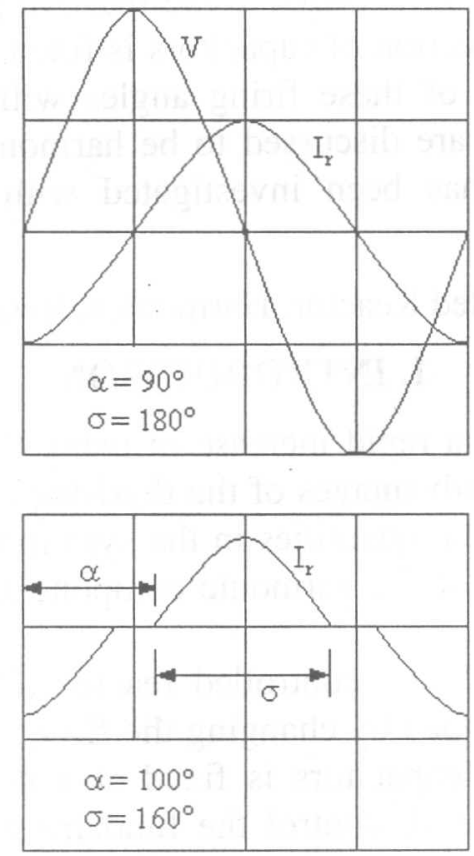

Figure 2. Voltage and current waveform of thyristor controlled reactor

Each thyristor is in conduction periodically in half cycle according to firing angle $\alpha$ and conduction angle $\sigma$ from the zero crossing of the voltage. There is a relationship between firing angle and conduction angle as the follows.

$\sigma=2(\pi-\alpha)$

Full conduction is obtained by firing angle of $90^{\circ}$. In this case the current is reactive and sinusoidal. There is a partial conduction between $90^{\circ}$ and $180^{\circ}$ as shown in Figure 2. 
VAR compensators consist of thyristor controlled reactors that are used for balancing the three phase systems supplying unbalanced loads and for preventing the voltage oscillations caused by short duration.loads in transmission and distribution systems.

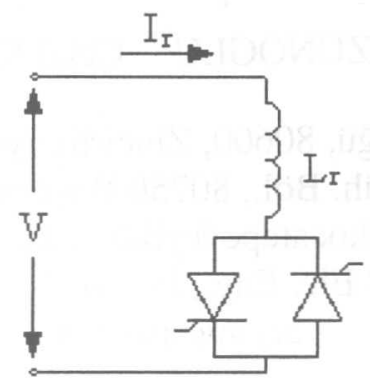

Figure 1. The main elements of thyristor controlled reactor

The thyristor-controlled reactor consists of reactor in series with two parallel inverse thyristors as shown in Figure 1. These thyristors are gated symmetrically and control the fundamental component of current versus time [3].
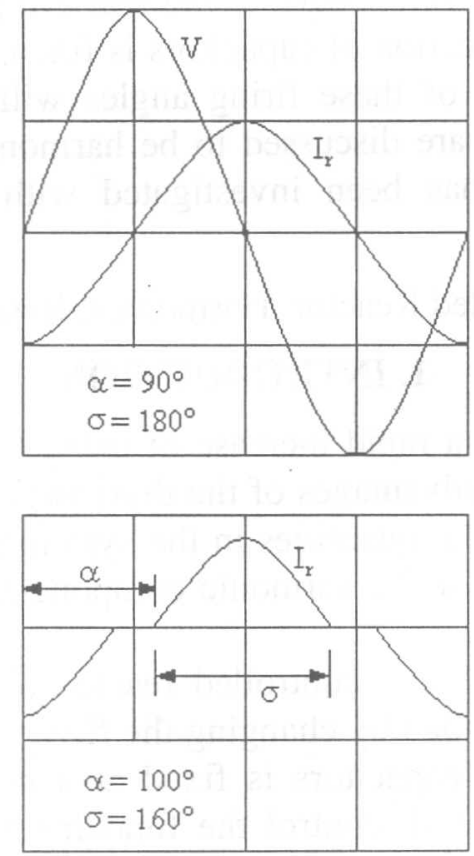

Figure 2. Voltage and current waveform of thyristor controlled reactor

Each thyristor is in conduction periodically in half cycle according to firing angle $\alpha$ and conduction angle $\sigma$ from the zero crossing of the voltage. There is a relationship between firing angle and conduction angle as the follows.

$\sigma=2(\pi-\alpha)$

Full conduction is obtained by firing angle of $90^{\circ}$. In this case the current is reactive and sinusoidal. There is a partial conduction between $90^{\circ}$ and $180^{\circ}$ as shown in Figure 2. 
Harmonics arise in thyristor controlled reactor because of phase control. TCl includes various harmonic components beside fundamental components of voltage a the edge of reactor and reactor current depends on firing angle $\alpha$ and conduction $\sigma$ angle.

In balanced loading TCR produces odd harmonics, but there will be no triple harmonics injected into the power system since triple harmonics flow within the $\Delta$. The percentage of current harmonic components $\mathrm{I}_{\mathrm{r}}{ }^{(\mathrm{h})}$ to that of fundamental components $\mathrm{I}_{\mathrm{r}}{ }^{(1)}$ is shown in Figure 3.

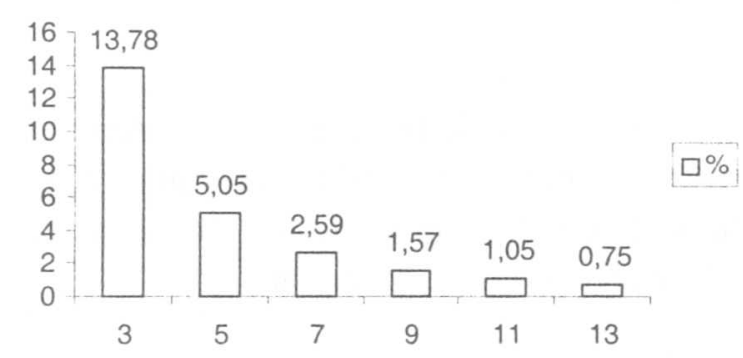

Figure 3. Maximum amplitude of harmonic currents in TCR

\section{STABILITY AND HARMONICS}

If there is increased load demand or variation in the system state, the system may become unstable with an uncontrollable decrease and increase in the voltage. The main reason for instability is insufficient condition of the power system corresponding to the demand of reactive power. This drawback may be remedied by use the static VAR compensator including TCR [6]. However, static VAR compensators cause instability in the power system on some operating conditions because of using power electronics to perform static VAR compensation.

One of the harmonic components of nonsinusoidal quantities may cause resonance in the system and uncharacterized harmonic components may occur. For this reason, it is required to pay attention to the operation of circuits including TCR, in order not to produce undesirable harmonics, which may cause discontinuity in the system. Stability analysis performed on the power systems show that instability conditions arise when resonance cases are involved.

\section{TCR AND RESONANCE CONDITIONS}

The installation of large capacitors to improve voltage and shift power factor causes very significant resonance problems in the power system. The resonance frequency of the system's inductive and capacitive reactance generally occurs near fifth and seventh harmonic. In addition to this, there may sometimes be seen resonance at leventh and thirteenth harmonics [7].

It is very difficult for a power system to withstand the large amount of harmonic urrents without any problem. Inductive reactance is proportional with frequency, but tpacitive reactance is inversely proportional with frequency. At the resonance zquency, capacitive reactance is equal to inductive reactance. If there is a resonance ar the harmonic frequencies in the system, there exists high amount of harmonic 
currents and voltage. These high amounts of currents and voltage occur when the capacitors used for compensation cause resonance with the inductance of the other circuit elements.

\section{METHOD OF ANALYSIS}

In this study, Fourier matrix method [3] and MATLAB software are both used to perform the resonance analysis. The reactor impedance versus conduction angle of the thyristors is given below [3]

$$
\mathrm{X}_{\mathrm{rh}}(\sigma)=\mathrm{j} \frac{\mathrm{hX}_{\mathrm{r}} \pi}{\sigma-\frac{\sin (\mathrm{h} \sigma)}{\mathrm{h}}}
$$

For the circuit given in Figure 4, the data of a system including TCR is entered and lower value of natural frequency $\omega_{\mathrm{ol}}$ and upper value of natural frequency $\omega_{\mathrm{ou}}$ are determined for the values of conduction angle $(\sigma)$ between $0^{\circ}$ and $180^{\circ}$. The natural frequency is determined by the following equation.

$$
\omega_{0}=\sqrt{\mathrm{X}_{\mathrm{ch}} / \frac{\mathrm{X}_{\mathrm{sh}}+\mathrm{X}_{\mathrm{rh}}(\sigma)}{\mathrm{X}_{\mathrm{sh}} \cdot \mathrm{X}_{\mathrm{rh}}(\sigma)}}
$$

where $X_{\mathrm{cn}}, \mathrm{X}_{\mathrm{sn}}$, and $\mathrm{X}_{\mathrm{rn}}$ are the nth harmonic component of capacitor reactance, nth harmonic of system reactance and nth harmonic of TCR reactance, respectively.

Existence of odd harmonics is examined. If odd harmonics are detected, then it is determined what values of the conduction angle $\sigma$ put the system into resonance between $0^{\circ}$ and $180^{\circ}$. Resonance condition for nth harmonic component is given by:

$$
\frac{\mathrm{X}_{\mathrm{sh}} \cdot \mathrm{X}_{\mathrm{rh}}(\sigma)}{\mathrm{X}_{\mathrm{sh}}+\mathrm{X}_{\mathrm{rh}}(\sigma)}=\mathrm{X}_{\mathrm{ch}}
$$

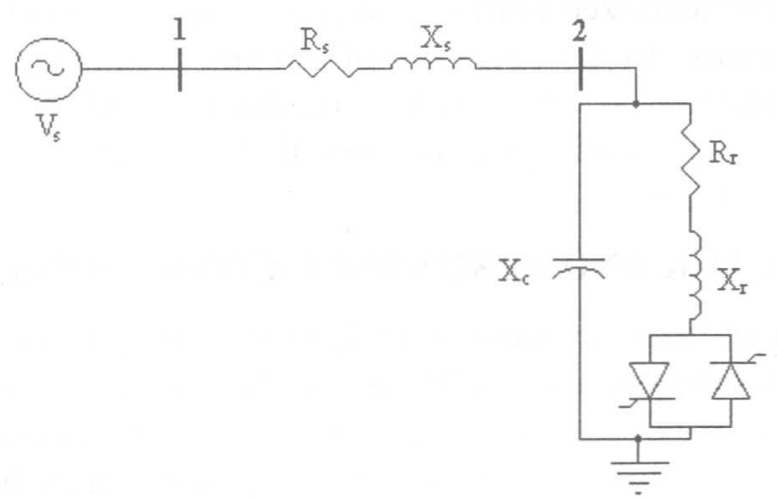

Figure 4. The sampled power system including FC-TCR

\section{NUMERICAL APPLICATION}

In this study, the circuit is modeled with Fourier matrix method and MATLAB software and the numerical application is performed and the results have been discussed 

Including Thyristor Controlled Reactor

when the TCR is used. The p.u. values of the system parameters are used and their values are: $\mathrm{V}_{\mathrm{s}}=1 \angle 90^{\circ}$ p.u, $\mathrm{Z}_{\mathrm{r}}=0.0735 \angle{ }^{\circ}$ p.u., $\mathrm{X}_{\mathrm{s}}=0.6268 \angle 87.14^{\circ}$ p.u., $\mathrm{X}_{\mathrm{c}}=1.77 \angle-90^{\circ}$ p.u.

First, Fourier matrix analysis is used. A computer program is written for implementation of the Fourier matrix analysis [8]. Using the same program a resonance analysis is conducted and the results are given in Table 1.

Table 1. Results obtained by Fourier matrix analysis

\begin{tabular}{|c|c|c|}
\hline \hline $\mathrm{h}$ & $\omega_{0 \mathrm{a}} \leq \omega_{0} \leq \omega_{0 \mathrm{u}}$ & $\begin{array}{c}\sigma, \text { conduction } \\
\text { angle (degree) }\end{array}$ \\
\hline 5 & $4.9077 \leq \omega_{0} \leq 5.1877$ & $41^{0} \leq \sigma \leq 70^{0}$ \\
\hline
\end{tabular}

Where;

$\omega_{0}$ is natural frequency

$\omega_{0 \mathrm{a}}$ is the lower value of natural frequency

$\omega_{0 u}$ is the upper value of natural frequency

$\mathrm{h}$ is harmonic frequency

$\sigma \quad$ is conduction angle.

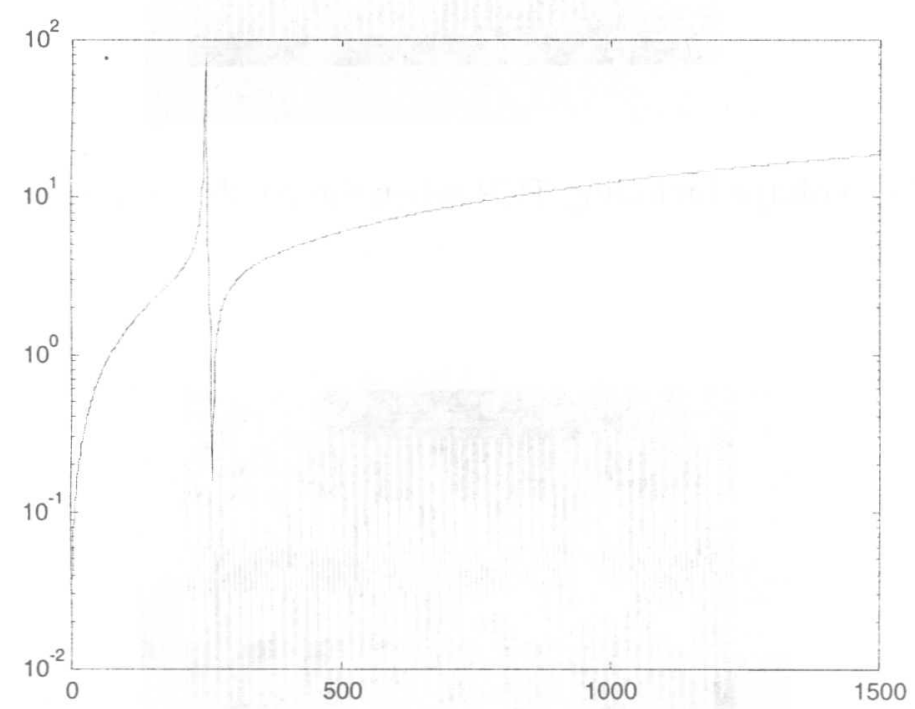

Figure 5. The impedance magnitude versus frequency at the bus including TCR

As it is seen from Figure 5, there exists a resonance near fifth harmonic and it occurs between the critical frequencies values of $240 \mathrm{~Hz}$ and $264 \mathrm{~Hz}$. These frequency values correspond to the conduction angle between $41^{\circ}$ and $70^{\circ}$ of TCR. The results obtained in Table 1 and the results obtained with the analysis done using MATLAB software are similar to each other. Thus, system is not stable for the conduction angels of between $41^{\circ}$ and $70^{\circ}$.

To verify the above analysis, the time domain analysis is done for the conduction angles inside and outside the range of $41^{\circ}$ and $70^{\circ}$. As a result of this last analysis the variation of the bus voltages including TCR are obtained as given in Figures 6 to 8 . 
340 Ramazan YÜKSEL, Mehmet UZUNOGLU, Celal KOCATEPE, Mehmet ARGIN

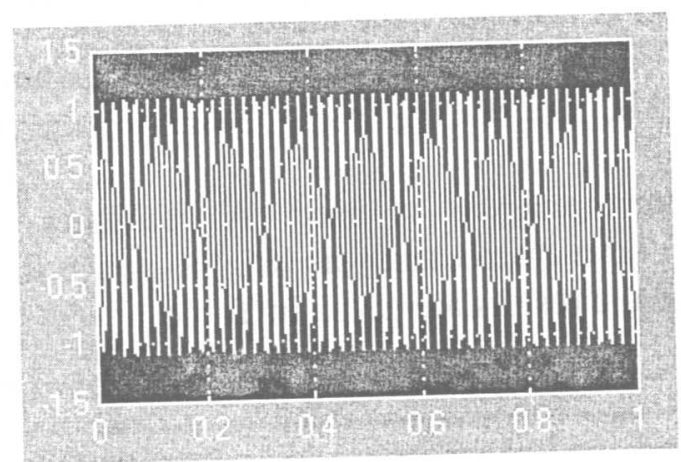

Figure 6. The bus voltage including TCR when the conduction angle is $20^{\circ}$ (stable case)

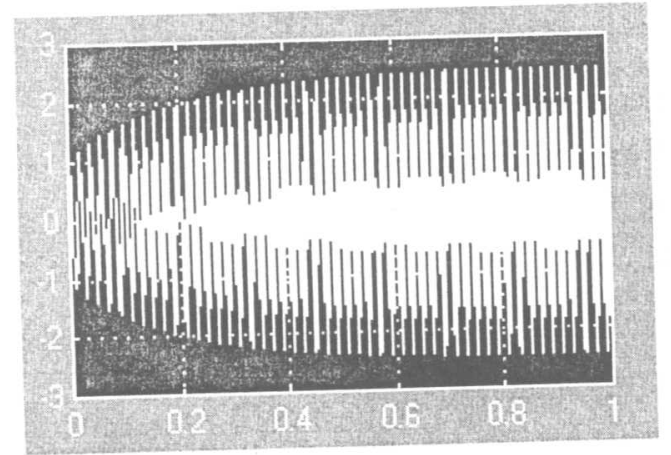

Figure 7. The bus voltage including TCR when the conduction angle is $55^{\circ}$ (unstable case)

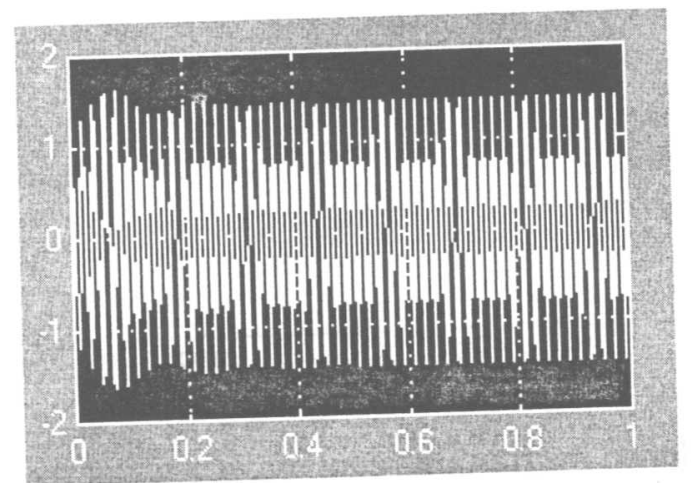

Figure 8. The bus voltage including TCR when the conduction angle is $160^{\circ}$ (stable case)

\section{CONCLUSIONS}

- Although use of thyristor controlled reactor with fixed capacitor or a group of capacitors for voltage stability and dynamic load factor improvement has many vantages, it causes harmonics and some undesired situations as a result of harmonics.

- Harmonics flowing in the power system can cause resonance and high distortion.

These cases have undesired effects on system stability; therefore the effects of 
harmonics should be analyzed.

- The operation point and parameter values of TCR should be determined with an analysis. TCR should be operated according to this analysis; otherwise these values may affect resonance frequency of system causing resonance.

- Possibility of system unstability arising from non-linear loads should be determined. If non-linear loads affect the system stability, then the harmonic components affecting the system stability have to be determined.

\section{REFERENCES}

[1] M. Uzunoglu, C. Kocatepe, R. Yumurtaci and K. Gulez, The Various Operating Conditions, Harmonics Effects and Stability of Thyristor Controlled Reactor, IEEE TENCON 2000, 24-27 September, Kuala Lumpur, Malaysia, 2000.

[2] W. Xu, J.R. Marti and H.W. Dommel, Harmonic Analysis of Systems with Static Compensators, IEEE Transaction on Power Systems, 1(6), 183-190, 1991.

[3] L.J. Bohmann and R.H. Lasseter, Equivalent Circuit for Frequency Response of a Static VAR Compensator, IEEE Trans.PWRS, 1(4), 68-74, 1986.

[4] L.J. Bohmann and R.H. Lasseter, Harmonic Interaction in Thyristor Controlled Reactor Circuits", IEEE Trans. PWRS, 3(4), 1919-1926, 1989.

[5] L. Gyugyi, Power Electronics in Electric Utilities: Static Var Compensators, Proceedings of IEEE, 4(76), 483-493, 1988.

[6] C.S. Indulkar, B. Viswanathan and S.S. Venkata, Maximum Power Transfer Limited by Voltage Stability in Series and Shunt Compensated Schemes for AC Transmission Systems, IEEE Transaction on Power Delivery, 2(4), 1246-1252, 1989.

[7] G. Chang, Harmonics Theory, Tutorial on Harmonics Modelling and Simulation, IEEE Power Engineering Society, 1998.

[8] M. Uzunoglu, C. Kocatepe, R. Yumurtacı and M. Tanrioven, Harmonics and Resonance Conditions in Thyristor Controlled Reactors, ELECO'99, Bursa, Turkey, 1999. 